\title{
Evaluating the rural health placements of the Rural Support Network at the Faculty of Health Sciences, University of Cape Town
}

\author{
Naidu CS, MSocSci, Junior Research Fellow; Irlam J, BSc Hon, Senior Lecturer; \\ Primary Healthcare Directorate, Faculty of Health Sciences, University of Cape Town \\ Correspondence to: Claudia Naidu, e-mail: claudia.naidu@uct.ac.za \\ Keywords: rural placements, undergraduate medical education, voluntary student society
}

\begin{abstract}
Objectives: The Rural Support Network (RSN) is an undergraduate student society that aims to raise awareness among the student body of the plight of rural health in South Africa, and organises individual and group placements in rural hospitals during vacations. This research aimed to evaluate these placements from the students' perspectives.
\end{abstract}

Design: In-depth, face-to-face interviews were conducted with 10 students and nine placement-reflective reports were reviewed. The data were analysed and coded for key themes using a constant, comparative grounded theory approach.

Setting: Faculty of Health Sciences (FHS) at the University of Cape Town.

Subjects: Students who had been on RSN placements in 2010.

Results: Students reported that the experience exceeded their expectations of learning new skills and observing and performing procedures. They gained significant insights into rural health care and were inspired to contribute to rural health in future. Their experiences helped them to gain confidence and an appreciation of the psycho-social aspects of patient care. The importance of community empowerment and of connecting and building relationships with communities was also emphasised. Challenges pertained to conflict within groups, incidents of unprofessional health care and being unable to help as much as they would have liked.

Conclusion: The study highlights the impact that positive experiences of rural health may have on health science students' interest in, passion for, and commitment to practising in underserved rural areas. Students' key recommendations for the FHS included the development of a rural programme within the undergraduate curriculum. Better group composition and improved planning and co-ordination of placements by the RSN were also recommended.

(P) Peer reviewed. (Submitted: 2011-10-19. Accepted: 2012-01-15.) ๑ SAAFP

S Afr Fam Pract 2012;54(4):352-357

\section{Introduction}

The chronic shortage of health professionals in South Africa is a well-documented crisis. ${ }^{1,2}$ The highly skewed distribution of health personnel between the private and public sectors, as well as between urban and rural areas, is of great concern.

Research has shown that rural-origin students are more likely to return to rural practice after completion of their studies. $^{3-6}$ Therefore, although the strategy of recruiting greater numbers of rural-origin students is gaining popularity, challenges remain. ${ }^{7}$ Undergraduate exposure to rural settings has been identified as an important factor in students' decisions to practise rural medicine. ${ }^{8}$ Smith et $\mathrm{al}^{6}$ studied the factors that influenced undergraduate health science students' career aspirations and choice of practice and found that participation in rural health club activities and rural placement experiences was significant. Similar results were found in other studies. ${ }^{9}$

The Rural Support Network (RSN) is an undergraduate student society that was formed in 1996 at the South African Medical Student Association general assembly at the University of Cape Town (UCT). The RSN aims to raise awareness among the UCT student body of the plight of rural health in South Africa. One of its objectives is to provide students with an insight into rural health and development by organising individual and group placements in rural hospitals during vacations.

This paper describes a qualitative evaluation, from the students' perspective, of the 2010 RSN rural health placements in order to make recommendations for the 
future placement programme. The study was approved by the UCT human research ethics committee (HREC ref. 116/2011).

\section{Method}

\section{Study population}

The study population consisted of all 50 RSN students who conducted placements in 2010, of whom 19 were first-year, eight second-year, seven third-year, 10 fourth-year and six fifth-year students.

\section{Sampling}

Students were placed in groups of between two and seven students at 12 sites across four provinces (Eastern Cape, Limpopo, KwaZulu-Natal and North West). The sample aimed to include one student from each site and to adequately represent each of the years of study. One or two students were randomly selected from each site using MS Excel $^{\circledR}$, giving a sample of 20 students. First-year students were over-represented and third- and fifth-year students were under-represented, so three substitutions were made to make the sample more representative. Students were contacted via e-mail and telephone, and the first 10 who indicated an interest in being interviewed were included in the final sample. This represented eight of the $12 \mathrm{RSN}$ placement sites used in 2010. Three were first-year, two were second-year, two were fourth-year and two were fifthyear students, while one was a sixth-year student. The six preclinical students in years one to three had less clinical experience than the other four, who had undertaken clinical clerkships.

\section{Data collection}

In-depth individual interviews of 15-20 minutes each were undertaken between April and June 2011 to elicit students' experiences of and perspectives on their rural placements and to discover how they interpreted these experiences. The researcher was guided by an interview schedule and probed students' responses in a neutral and nonleading manner. The interviews were audio recorded with respondents' consent and later transcribed. Interview data were supplemented by thematic analysis of placementreflective reports which students were encouraged to submit about their experiences. In this way, methodological triangulation facilitated the validation of the data through cross-examination of themes and key findings across the interview and report data. All nine available reports, two of them written by interviewed students, were reviewed.

\section{Data analysis}

The interview and report data were analysed and coded for key themes using a constant-comparative grounded theory approach. $\mathrm{NVivo}^{\circledR}$, a qualitative data analysis software programme, was used. Broad categories (tree nodes) were developed from the research questions and subcategories (free nodes) were developed directly from the responses.

\section{Findings}

The findings are summarised around the key themes that emerged from the interviews and placement reports. All quotes derive from the interview data.

\section{Expectations}

Students expected to encounter poverty $(n=5)$, limited resources $(n=4)$, small and busy clinics $(n=4)$, understaffing $(n=3)$, poor hospital management $(n=1)$ and poor service delivery $(n=1)$ in rural settings. Nevertheless, they were surprised to find fully functioning hospitals that appeared to manage comfortably despite their resource constraints $(n=6)$ :

"I was expecting to see all these like poor places kind of thing and under-resourced areas ... but it was quite amazing because they don't have a lot of sophisticated things like at GSH, but they actually do work with what they have and they make it work." (LN, fifth-year student, Holy Cross Hospital, Eastern Cape).

Given these expectations, two students felt that their environments had not been "rural enough":

"I wouldn't say that particular setting was of a rural standard. It was in the standing of a secondary hospital in Cape Town. So from that perspective, I didn't get to see the actual social ... the depth of the problems associated with what we perceive to be rural health care." (KM, fourth-year student, Taung Hospital, North West).

One student commented on her shock on finding that there was not one local doctor at the facility where she was based. Another admitted to expecting to live in a hut and to fetch water from wells and was surprised to find that her accommodation was well furnished with electricity and running water. This surprise was shared by another student, who had also anticipated the bare minimum. Two students assumed that they would encounter communication difficulties with patients due to the language barriers, but found this to be easily manageable instead.

Students came to realise that "rural life" was not as dire as they had expected it to be $(n=3)$, or not as the media sometimes portray it to be $(n=1)$ :

"Sometimes you think rural community is hostile and they're always upset and almost hating the world, and always complaining ... but when I was there, I was showered with love ..." (NM, first-year student, Donald Fraser Hospital, Limpopo).

Members of staff at the hospitals were very friendly, welcoming and open $(n=7)$ and very willing to teach $(n=6)$ : 
Table I: Key lessons and insights

\begin{tabular}{|c|c|c|}
\hline Theme & Subtheme & Interviews and reports embodying the theme \\
\hline \multirow[t]{2}{*}{ Clinical learning activities } & Performed new procedures & 8 \\
\hline & Observed new procedures & 7 \\
\hline \multirow[t]{2}{*}{ Learning opportunities } & Applied learning to practice & 3 \\
\hline & Built confidence through doing & 3 \\
\hline \multirow[t]{5}{*}{ Inspiration } & To be a good doctor & 2 \\
\hline & To go "beyond theory" & 2 \\
\hline & To always do one's best & 1 \\
\hline & To be grateful & 1 \\
\hline & Honour of becoming a rural doctor & 1 \\
\hline \multirow[t]{5}{*}{ Exposure } & Rural health problems & 7 \\
\hline & Rural settings & 5 \\
\hline & Differing degrees of "rural" & 3 \\
\hline & Hospital settings & 3 \\
\hline & Engaged with different cultures & 2 \\
\hline \multirow[t]{8}{*}{ Deeper understandings } & Psycho-social aspects of patient care & 7 \\
\hline & Need to be in rural environment & 7 \\
\hline & Meaning of primary health care & 3 \\
\hline & Communication and teamwork & 3 \\
\hline & Importance of understanding patients' language & 3 \\
\hline & Importance of building relationships with communities & 3 \\
\hline & Importance of community empowerment & 2 \\
\hline & Importance of trust and respect towards patients & 1 \\
\hline
\end{tabular}

Table II: Student quotes illustrating key lessons and insights

\section{Learning opportunities}

"You read textbooks and you look at diagrams, but when you are there and it's before you, you think that this is not like any diagram I've ever seen in my life. That was pretty scary."

First-year student

\section{Exposure}

"But when I got there, I felt this is where I needed to be, this is where I think as a doctor, I will be most appreciated by the patients."

"I realised that there is a great need for development in the area of rural medicine. I think a lot of newly trained doctors just want to go to the city and overseas, we don't quite know what's out there for us."

"It can help me build my knowledge of how to advocate for these things ... for a person who hasn't seen these things, they will be less prepared than I would be, as I have experienced things that you can't get in the textbook."

"There's politics, there's dilemmas, there's problems, and there's real people to deal with it, there's your own emotions.

The biggest thing is medicine is really messy and very complicated, and it's something you can only learn once you leave university."

\section{Deeper understanding}

"The core things they are teaching us ... now that I'm actually doing it, I see the importance of how to approach patients and how you should communicate with them."

"It helped me to put into perspective the public health issues... It makes more sense and has much more value when dealing with people and not stories."

"It was eye-opening as to what the admin is like, what the clinical staff is like, what the nurses are like, things like community development, sitting on an interdisciplinary committee."

"The actual psycho-social, going beyond the patient kind of stuff, after being there, I actually considered that. I actually learnt it's really important."

"When I got to the clinic, it was more 'I want to be a doctor', it was not people-centred it was more me-centred so it really changed that. I really saw how much the people need the services. I actually saw how much of a difference we can actually make. As I study now, it's because I need to know, in the future I will be applying what I learn to help someone else."

Second-year student

Fifth-year student

Third-year student

First-year student

First-year student

First-year student

Fourth-year student

Second-year student

First-year student 
"Hands on, everybody there was willing to drive our learning experience and they were also willing ... to give us a little more medical exposure and create an environment to learn." (KM, fourth-year student, Taung Hospital, North West).

Students reported that their experiences exceeded their expectations of learning new skills and observing and performing procedures. Only one student had expected to undertake more and felt that there had been insufficient guidance from the staff at the facility.

\section{Significant lessons and insights}

Table I summarises the keys lessons and insights that students learnt and gained through their placement experiences. The key themes are illustrated by verbatim quotes in Table II. Students learnt a great deal from being able to observe and perform procedures to which they had never been exposed before. They valued the practical experience and considered the exposure to rural and hospital settings to be a good foundation for future work. Their experiences provided a greater understanding of what is taught at medical school and inspired them to be a "good doctor" and go "beyond theory".

The encounters and experiences that students felt strongly about varied immensely. Their exposure to death and illness was cited as being painful, frustrating and emotional $(n=4)$.

They were also touched by the joy of rural health care and the dedication, compassion and unity of staff $(n=3)$ :

"The staff, everyone that is working there ... they have a very deep compassion, like they really care about the patients, and it shows, and they do it every day. That touched me." (BS, fifth-year student, Madwaleni Hospital, Eastern Cape).

Some students reported disappointment, annoyance and anger with the system $(n=2)$, uncommitted doctors $(n=1)$ and a politicised hospital administration $(n=1)$. Frustrations with and concerns about the extent of the resource and access problems faced by rural society were also voiced $(\mathrm{n}=7)$ :

"The extent to which people are experiencing them (social problems) are vastly and several times removed from the levels of problems in the urban areas so getting exposure to that social aspects and the extent to which people can't come to hospital, it's sort of exaggerated in that area. That was worrying and concerning." (KM, fourth-year student, Taung Hospital, North West).

\section{Changed attitudes to studies and career aspirations}

The experience enlightened two senior students to the idea of "knowing a little bit about everything" rather than limiting oneself to specialisation in one area of medicine. One student felt motivated and inspired to continue her studies and complete her Master's in public health. Another student remarked that she was now training "to make a difference":

"The placement has changed that mindset and I'm making it a point in my life to help those in rural areas. I want to make a difference in my community and also in our country." (GM, first-year student, Donald Fraser Hospital, Limpopo).

The placement experience cemented students' passion and eagerness to work in and contribute to rural health $(n=9)$. For others $(n=3)$, it also clarified the roles that they would like to fulfil in rural health care:

"Personally, being exposed to the staff shortage in the 'real world' has made me realise the intense hope and faith patients have in doctors, making me want to serve where the problem lies: the first entry level of our healthcare system."(NM, first-year student, Donald Fraser Hospital, Limpopo).

One student commented on the need to find a balance between rural and urban life in light of concerns that a purely rural life would not suit family living or provide opportunities for further academic learning. Concerns about family and raising children in a rural environment were raised by another student.

\section{Challenges}

Table III summarises the main challenges faced by students during their placements.

Table III: Challenges experienced during rural placements

\begin{tabular}{l|c|}
\hline Subthemes & $\begin{array}{c}\text { Interviews and reports } \\
\text { embodying the theme }\end{array}$ \\
\hline Professional lapses & 6 \\
\hline Group discord & 3 \\
\hline $\begin{array}{l}\text { Inability to help as much as students } \\
\text { would have liked }\end{array}$ & 3 \\
\hline Difficulties with nurses & 2 \\
\hline Community ignorance & 1 \\
\hline Limited multidisciplinary teams & 1
\end{tabular}

Students felt that patients were unaware of their rights, and they cited violations of these rights by staff, including lack of confidentiality, privacy, dignity, respect and proper engagement with patients.

"Sometimes though they are right there with the doctor, they don't feel that they really got a consult and I don't think they know much about their rights. So that was a bit hard ..." (BN, second-year student, Cala Hospital, Eastern Cape).

One student reported that nurses seemed insecure and threatened by the students' presence, and another student said that nurses accused students of not helping enough: 
"It's like when you reach the hospital, it's like they feel we going to take their jobs or something which just wasn't a good impression."(GM, first-year student, Donald Fraser Hospital, Limpopo).

Group dynamics posed a challenge for some students who found it difficult to compromise and accommodate the conflicting opinions and desires of team members. Other challenges included doctors not understanding the value of health and rehabilitation, tiredness and environmental conditions such as water shortages.

\section{Recommendations for faculty and future placements}

Students suggested a number of recommendations for future rural placements, both for the faculty and the RSN committee. Table IV summarises these recommendations and Table $\mathrm{V}$ provides illustrative quotes.

Recommendations for the RSN were that future groups should consist of both preclinical and clinical students, so that seniors can teach and guide juniors and so that the groups are larger than two members.

Table IV: Recommendations for future placements

\begin{tabular}{|l|c|}
\hline Themes and subthemes & $\begin{array}{c}\text { Interviews and } \\
\text { reports embodying } \\
\text { the theme }\end{array}$ \\
\hline Health Sciences Faculty & 5 \\
\hline Exposure to rural health setting & 3 \\
\hline Introduction of compulsory rural block into \\
curriculum
\end{tabular}

In terms of process, students suggested that the expectations and objectives of the placements should be clarified to students, as well as the rural facility where they are to be placed $(n=5)$. Students would like an adequate introduction to what the placement is about and what they should be doing, and sufficient guidance on what else to expect prior to the placements.

Improvements in planning $(\mathrm{n}=7)$, advertising $(\mathrm{n}=1)$ and management $(n=1)$ were also proposed. These include timely administrative preparations that emphasise the value of daily journals during the placements as reflective tools and to extend awareness to allied health science students:

"It's just nice to know at least a week (in advance) where you going, what's going on but even a few days before we left I was so unsure." (KA, first-year student, Empilisweni Hospital, Eastern Cape).

Students also felt that it was important for the RSN to maintain contact with the rural hospitals throughout the year $(n=1)$ and to advocate for them where possible $(n=1)$ :

"We must do something about what we see and about their needs ... we need to advocate. It's a two-way relationship, when we go there we learn and we need to do something in return."(MG, third-year student, Emmaus Hospital, KwaZulu-Natal).

\section{Limitations}

The limitations of the study were the small sample and the fact that the results are not generalisable as per the nature of qualitative studies. The self-reported nature of the data introduced the possibility of reporting bias. Although a random sample of students was invited to participate, the inclusion of only those who were the first to respond is a potential selection bias as non-respondents might not have been as positive about the placements.

\section{Conclusion}

This study highlights the impact that a positive experience of rural health might have on health science students' interest in, passion for and commitment to practising in underserved rural areas. This is significant as it has

Table V: Student quotes illustrating key recommendations

"The opportunity can make a difference in anybody's life, and I believe it is something that all students studying to
become a healthcare professional in this country should consider."
"Every med student should be forced to do some rural work... I think a lot of people decide against it without really
knowing what it's about, without really understanding the need."
"You could teach the clinical theory which they might have forgotten and clinical could teach you ..."
"You need to work with a doctor, at least one, who knows that these are students and know their responsibilities and
know what they are expecting from you ... there's that gap."
"I can understand what the essence of the placement is - it is about learning. But what kind of learning? I think those
things need to be fleshed out a lot more."


been noted elsewhere that South African health science faculties may not be doing enough to provide valuable rural experiences, and to undergraduate students in particular. ${ }^{3}$ The placements offered students experience of the positive and negative aspects of rural practice and provided them with an insight into what rural life is like. The placements also provided opportunities to deal with ethical dilemmas such as witnessing professional lapses by nursing and medical staff. This is not unique to this study. ${ }^{13,14}$ Exposure to death and illness, and to the difficulties of working with limited resources and infrastructure, further helped to prepare students for their future roles and responsibilities.

While students cited challenges to family and social life in rural practice, as well as to career development prospects and further training, they appeared to have been drawn to the need for improved and accessible health care in rural communities. Students were asked whether or not their experiences would have any impact on their approach to future studies and career paths. Future studies should assess how the clinical exposure provided by these placements might influence students' later academic performance and attitudes towards learning and clinical skills development. A follow-up longitudinal study might be useful to evaluate how these placements influenced students' choice of specialty and location of practice in the long term.

Students' key recommendations for the faculty included the development of a rural programme within the undergraduate curriculum, as well as ongoing lectures and seminars on rural health. Improved planning and co-ordinating of placements was recommended for the RSN. This should include greater attention to group composition and adequate orientation prior to the placements for students and rural facility staff.

Briefing and counselling sessions before and after placements to discuss issues pertaining to patient ethics, coping with death and quality improvement of patient care might also be helpful. Finally, the RSN should continue to seek new and innovative methods to generate awareness of and interest in the society among all health science students, particularly those with minimal awareness of rural health.

\section{Acknowledgments}

This research was funded by the Collaboration for Health Equity through Education and Research (CHEER). We would like to thank the students for their valuable participation in this research.

\section{References}

1. Van Rensburg D, Van Rensburg N. Distribution of human resources. In: Crisp N, Ntuli A, editors. South African health review 1999. Durban: Health Systems Trust; 1999

2. Kautzky N, Tollman SM. A perspective on primary health care in South Africa. In Barron P, Roma-Reardon J, editors. South African health review 2008. Durban: Health Systems Trust; 2008

3. Couper ID, Hugo JFM, Conradie H, et al. Influences on the choice of health professionals to practise in rural areas. SAfr Med J. 2007;97(11):1082-1086.

4. Brooks RG, Walsh M, Mardon RE, et al. The roles of nature and nurture in the recruitment and retention of primary care physicians in rural areas: a review of the literature. Acad Med. 2002;77(8):790-798.

5. Orpin $P$, Gabriel $M$. Recruiting undergraduates to rural practice: what the students can tell us. Rural Remote Health. 2005;5(4):412-426.

6. Smith $L$, Hall A, Langelaan $F$, et al. Factors affecting the career decisions of health students: will they go rural? Data from the NRSHN Impact Survey 2009 Cairns, Australia: $10^{\text {th }}$ National Rural Health Conference; 2009 [homepage on the Internet]. c2011. Available from: http://10thnrhc.ruralhealth.org.au/papers/docs/ Smith_Luke_E4.pdf

7. De Vries E, Reid SJ. Do South African medical students of rural origin return to rural practice? S Afr Med J. 2003;93(10):789-793

8. Geyman JP, Norris TE, Hart G. Textbook of rural medicine. New York: McGraw-Hill; 2001

9. Tavernier LA, Connor PD, Gates D, Wan JY. Does exposure to medically underserved areas during training influence eventual choice of practice location? Med Educ. 2003;37(4):299-304.

10. Rabinowitz HK, Diamond JJ, Markham FW, Paynter LP. Critical factors for designing programs to increase the supply and retention of rural primary care physicians. JAMA. 2001;286(9):101-148

11. Zink $T$, Center $B$, Finstad D, et al. Efforts to graduate more primary care physicians and physicians who will practice in rural areas: examining outcomes from the University of Minnesota-Duluth and the Rural Physician Associate Program. Acad Med. 2010:85(4):599-604.

12. Stagg P, Greenhill J, Worley PS. A new model to understand the career choice and practice location decisions of medical graduates. Rural Remote Health 2009:9(4):1234-1245

13. Vivian L, Naidu CS, Keikelame JM, Irlam J. Medical students' experiences of professional lapses and patient rights abuses in a South African health sciences faculty. Acad Med. 2011;86(10):1282-1287.

14. Ginsburg S, Regehr G, Stern D, Lingard L. The anatomy of the professional lapse: bridging the gap between traditional frameworks and students' perceptions. Acad Med. 2002;77(6):516-522. 